\title{
MICROENCAPSULATED LEMONGRASS OIL FOR MOSQUITO REPELLENT FINISHING OF KNITTED COTTON WEAR
}

\author{
VINAYAGAMOORTHY P ${ }^{1}$, SENTHILKUMAR B ${ }^{2}$, PATCHIYAPPAN KM ${ }^{3}$, KAVITHA R ${ }^{4}$ \\ ${ }^{1}$ Research Scholar, Research and Development Center, Bharathiyar University, Coimbatore, Tamil Nadu, India. ${ }^{2}$ Department of Rural \\ Industries and Management, Gandhigram Rural Institute-DU, Chinnalapatti, Tamil Nadu, India. ${ }^{3}$ Department of Costume Design \\ and Fashion, PSG College of Arts, Coimbatore, Tamil Nadu, India. ${ }^{4}$ Department of Home Science, Mother Teresa Womens University, \\ Tamil Nadu, India. Email: senthil.b1980@gmail.com
}

Received: 21 February 2017, Revised and Accepted: 27 March 2017

\section{ABSTRACT}

Objective: This study was conducted to design the textile structure with mosquito repellent behavior using microencapsulated lemongrass extract.

Methods: Lemongrass oil extracted from Cymbopogon citratus by a hydro distillation process, which was used as core and gum acacia was used as wall material. About $10 \% \mathrm{~W} / \mathrm{V}$ gum acacia was allowed to swell with hot water and stirred well with a temperature of $50^{\circ} \mathrm{C}$. Further to this mixture $10 \mathrm{ml}$ of lemongrass extract was mixed and stirred around $400 \mathrm{rpm}$ for 15 minutes. Subsequent with this process, $20 \% \mathrm{~V} / \mathrm{V}$ sodium sulfate was added then the stirrer speed was reduced $80 \mathrm{rpm}$, and then $5 \mathrm{ml}$ of $17 \%$ formaldehyde was added along with this mixture. Finally, the microcapsules were obtained. Then, this lemongrass extract capsule mixture was coated on the fabric through pad dry cure method.

Results: Mosquito repellent study was carried out through the excito chamber method and assessed the mosquito repellency percentage. The maximum mosquito repellency percentage was obtained around $90 \%$. Wash durability, abrasion resistance, air permeability, and bursting strength of the coated textiles were also studied. Scanning electron microscopy analysis and gas chromatography analysis were also performed for the samples.

Conclusion: It was proved that lemongrass microencapsulated textiles provide good resistance against mosquito bites and also concluded that this process is one of eco-friendly.

Keyword: Mosquito repellent textile, Lemongrass, Cotton, Single jersey fabric.

(C) 2017 The Authors. Published by Innovare Academic Sciences Pvt Ltd. This is an open access article under the CC BY license (http://creativecommons. org/licenses/by/4. 0/) DOI: http://dx.doi.org/10.22159/ajpcr.2017.v10i6.18077

\section{INTRODUCTION}

Mosquitoes are the important vectors of diseases through transmitting pathogens. They are one of the primary causes for spreading diseases to the human being [1]. The genus Aedes mosquitoes are the main causes for urban yellow fever in worldwide. Around 120 million people in the world have been infected due to mosquito bites, and 4 million people are having common chronic manifestation [2]. Few of the arthropod-borne diseases are preventable through vaccines but not in the case of diseases such as malaria and dengue. Hence, avoiding Mosquito bites are the only way to protect the individual from these diseases [3]. At present, the personal protective measures are taken from mosquito bites through applying mosquito repellant as skins lotions, coils, creams, and liquidators are providing limited support [4]. Coating of suitable mosquito repellant over the clothing is an innovative method to avoid mosquito bites as the large portion of human body is coved [5]. This has necessitated the development of mosquito repellent fabrics. It is one of the revolutionary ways to produce the coated mosquito repellent clothes has a capacity of driving away the mosquitoes [6]. Mostly synthetic chemical larvicides applied for controlling mosquitoes, but most of these coating are toxic to human. Therefore, researchers are currently exploiting natural, eco-friendly substances as insecticides for controlling larval mosquitoes [7]. Various eco-friendly natural oils have been reported as mosquito repellents due to their eco-friendly and biodegradable nature such as citronella, cedar, verbena, pennyroyal, geranium, lavender, pine, cajeput, cinnamon, rosemary, basil, thyme, allspice, garlic, and peppermint [8]. Petroleum ether and methanol extracts of V. negundo show significant reduction of consumption and utilization of food and thereby bringing about antifeedancy to Tribolium castaneum [9]. In general, microencapsulation technology increases the durability of the textile coating. A microcapsule stores a certain amount of functional agent and protective shield from the effects of moisture and sunlight. This functional agent is diffused through the wall of the capsule in a regular interval so that this technology could provide the durable finish to the textile substrate [10]. Similar to that microencapsulated Andrographis paniculata plant extracts treated cotton fabric showed good antimicrobial activity and its wash durability also showed better performance [11]. This present research work intended to develop a mosquito repellent plan-knitted fabric using lemongrass extract.

\section{MATERIALS AND METHODS}

\section{Materials}

Lemongrass extract was used a coating agent for mosquito repellant and purchased from M/S Naga natural products, Dindigul, Tamil Nadu. Plan-knitted single jersey cotton fabric of 240 GSM was scoured and bleached well with alkali and peroxide, respectively. Gelatin and gum Arabic were used as shell formation compound, which was sourced from GVR enterprises, Madurai.

About $100 \%$ low-twisted cotton yarn is knitted through plain and rib knitted structures. Both the fabrics were scoured and bleached with sodium hydroxide and hydrogen peroxide, respectively. Subsequently, dyeing was carried out using hot brand reactive dye.

\section{Preparation of microcapsules}

Mosquito repellent treatment was approached through microencapsulation technic over cotton knitted fabric. Lemongrass oil extracted from Cymbopogon citratus by hydro distillation process [12]. It was used as core material gum acacia as wall material. About $10 \%$ $\mathrm{W} / \mathrm{V}$ gum acacia was allowed to swell with hot water. To this mixture, $50 \mathrm{ml}$ of hot water was added and stirred well with a temperature of 
$50^{\circ} \mathrm{C}$. Further to this mixture, $10 \mathrm{ml}$ of lemongrass extract was mixed, and stirrer speed was maintained around $400 \mathrm{rpm}$ for 15 minutes. Followed by this process, $20 \% \mathrm{~V} / \mathrm{V}$ sodium sulfate was added then the stirrer speed was reduced $80 \mathrm{rpm}$ and then $5 \mathrm{ml}$ of $17 \%$ formaldehyde was added along with this mixture. The microcapsules were obtained by decantation and washed with isopropyl alcohol followed by drying at the temperature of $45^{\circ} \mathrm{C}$ for $12 \mathrm{hrs}$.

\section{Coating process over knitted fabric}

The lemongrass extract capsule mixture was coated on the fabric through pad dry cure method. As reported by Golji the finishing of this agent through binder compound such as polyurethane, acrylic to fix the microcapsule over the surface of the fabric, which enables the last longing effect [13]. A finishing bath was prepared with prepared microsules, $15 \% \mathrm{~V} / \mathrm{V}$ of acrylic crosslinking agent and remaining quantity of softener (Perisoft Nano, Bayer). The cotton knitted fabric was immersed in this solution pneumatic padding mangle, squeezed, and then dried at $80-85^{\circ} \mathrm{C}$ in an oven.

\section{Characterization}

\section{Mosquito repellency testing}

The mosquito repellent activity was tested through excito chamber method (Roberts et al., 1997). With Anopheles variety of mosquitoes specially designed two-excito-repellency test chambers were used as per Fig. 1 to evaluate the efficiency of repellency activity. The wooden outer chamber of excito-repellency testing device measures $34 \mathrm{~cm} \times$ $32 \mathrm{~cm} \times 32 \mathrm{~cm}$ and faces the front panel with the single escape portal. The mosquito escape zone includes an outward projecting funnel with the dimension of $14 \mathrm{~cm}$ long in its top and bottom exit funnel, leaving $1.5 \mathrm{~cm}$ wide (a horizontal slit) through which mosquitoes escape from the chamber. The back size of the metal door is a hinged metal door, which tightly closed. The back side consists of mosquito exposure zone having is a hinged metal door, which also contains an inner removable panel. This panel fits inside the back of the exposure chamber, in addition to this 4 small flanges were available along with this chamber to serve the imprison the mosquitoes. The Plexiglas helps to observe the mosquitos' population inside the chamber.

This test consists of 4 group of 25 mosquitoes were introduced into this chamber for 1 minute. Before conducting the experiments, mosquitoes were deprived of all nutrition and water for a minimum of $4 \mathrm{hrs}$ before exposure. Laboratory tests were performed during daylight hours only. Before initiating the testing procedure, the exit funnels were sealed, and mosquitoes were permitted exposureto the chamber without test specimen, which ensures the mosquitoes to adjust the test chamber condition and funnel was opened then the mosquito repellent-treated fabric was kept in the chamber, and one by one all the group of 25 mosquitoes were exposed in the chamber for 1 minute. A number of escaping mosquitoes from the chamber were recorded manually at 1 minute intervals of 5 minutes of observation. A survival analysis approach was used to estimate the rates of mosquitoes escaping from chambers. In the excito-repellency test, there are only 2 possible outcomes for a specimen: It will either escape or not escape from the exposure chamber (Mosquitoes escaped are treated as death)

$$
\% \text { mosquito repellency }=\frac{\begin{array}{l}
\text { Number of specimenescaped } \\
+ \text { number of specimendead }
\end{array}}{\text { Number of specimenexposed }} \times 100
$$

\section{Wash durability analysis}

As per the AATCC 124-2009, the samples were washed in a front loading washing machine in a $5 \%$ neutral soap solution for 20 minutes and dried. This process was repeated 10 washes, 20 washes, and 30 washes for the microencapsulated samples. Mosquito repellency test was carried out for all the samples, which ensured the wash durability of the coated samples.

\section{Scanning electron microscopy (SEM)}

SEM analysis was peformed to inspect the morphology of coated knitted fabric. The textile sample treated with microencapsulated mosquito repellent coating supposed to form a rough coating over the fiber surface of the clothing. The imaging was done with $\times 500$ and $\times 2000$ magnification at $5 \mathrm{kV}$.

\section{Gas chromatography-mass spectrum (GC-MS) analysis}

The component identification of the lemongrass extract was performed by GC-MS analysis and the spectral data of the sample were investigated. After the sample had been subjected to washing, the analysis was carried out using Hewlett Packard GC-MS system, which consisted of a model 5890A GC, a model 5970 mass selective detector, HP 5970C MS ChemStation software a HP 7946 disc drive. A fuced silica capillary column coated with HP-5 cross-linked 5\% phenylmethyl silicone (SE-54, $0.33 \mathrm{~mm}$ film thickness) was used. The GC temperature schedule was as follows: Initial temperature was $100^{\circ} \mathrm{C}$ for 1 minute, increased to $130^{\circ} \mathrm{C}$ at the rate of $2^{\circ} \mathrm{C} /$ minute, then increased to $200^{\circ} \mathrm{C}$ at the rate of $3^{\circ} \mathrm{C} /$ minutes, and finally increased to $280^{\circ} \mathrm{C}$ at the rate of $6^{\circ} \mathrm{C} /$ minute for 10 minutes. The split ratio of $1: 12$, injection temperature was $250^{\circ} \mathrm{C}$, transfer line temperature was $270^{\circ} \mathrm{C}$, and iron source temperature was $200^{\circ} \mathrm{C}$. The mass spectrometer was operated at $70 \mathrm{eV}$ in the electron impact mode with SCAN or selected ion monitoring. Once the sample is presented in the vial, the microcapsules were tripped due to simultaneous pressing with the rod, before closing the vial. The volatile component in the capsule spread out in the gas phase until the headspace reaches a balance. It was studied for the period of $24 \mathrm{hrs}$. Subsequent to this testing, $0.5 \mathrm{~mL}$ of headspace gas was collected and injected with GC-flame ionization detection equipment for further analysis.

\section{Abrasion resistance}

Abrasion resistance was tested using Martindale abrasion tester. This tester gives a controlled amount of abrasion between fabric surfaces at comparatively low-pressure environment. A circular specimen of fabric was abraded with simple harmonic motion. The resistance of abrasion was estimated by finding the loss in mass of the specimen.

\section{Bursting strength}

It is the measure of pressure required to rupture fabric. The selected bursting strength tester is working under the hydraulic bursting. According to IS0-13938-1 standard, the testing was executed. The sample tested will be clamped over the testing diaphragm and clamped with the ring. The amount pressure exerted on the sample for bursting through diaphragm was measured.

\section{Air permeability}

This testing was carried out with digital air permeability tester. The working principle of this instrument is that air is drawn through a specified area of the fabric, which is adjustable to suit specific textiles being evaluated.

\section{RESULTS AND DISCUSSION}

\section{Mosquito repellency}

The percentage was assessed through percentage of insects dead due to mosquito repellent treated fabric was calculated using the equation 1 . The analysis was conducted in three different samples such as controlled sample, lemongrass-encapsulated fabric before wash, lemongrassencapsulated fabric after 10 wash, lemongrass-encapsulated fabric after 20 wash, and lemongrass-encapsulated fabric after 30 wash. The consolidated report of mosquito repellent activity is shown in Table 1.

From the analysis, it is clear that the controlled samples showed no repellent activity against mosquitoes. Whereas, mosquito repellent encapsulated sample (before washing) generated a higher level of mosquito repellent activity as compare with other samples. The ANOVA study was carried out to measure the statistical significant 
Table 1: Mosquito repellent activities of various stages of lemon grass encapsulated cotton knitted fabric

\begin{tabular}{|c|c|c|c|c|c|c|}
\hline Fabric & Samples & $\begin{array}{l}\text { Specimens } \\
\text { exposed (Nos) }\end{array}$ & $\begin{array}{l}\text { Specimens in } \\
\text { the cage (Nos) }\end{array}$ & $\begin{array}{l}\text { Specimens } \\
\text { escaped (Nos) }\end{array}$ & $\begin{array}{l}\text { Specimens } \\
\text { dead (Nos) }\end{array}$ & $\begin{array}{l}\text { Mosquito repellency } \\
\text { percentage }\end{array}$ \\
\hline 1 & \multirow[t]{5}{*}{ Controlled sample } & 25 & 25 & 0 & 0 & 0 \\
\hline 2 & & 25 & 25 & 0 & 0 & 0 \\
\hline 3 & & 25 & 25 & 0 & 0 & 0 \\
\hline 4 & & 25 & 25 & 0 & 0 & 0 \\
\hline 5 & & 25 & 25 & 0 & 0 & 0 \\
\hline 1 & \multirow[t]{4}{*}{ Lemongrass encapsulate } & 25 & 2 & 9 & 14 & 92 \\
\hline 3 & & 25 & 4 & 6 & 15 & 84 \\
\hline 4 & & 25 & 3 & 9 & 13 & 88 \\
\hline 5 & & 25 & 3 & 10 & 12 & 88 \\
\hline 1 & \multirow[t]{5}{*}{ Lemongrass encapsulate-10 wash } & 25 & 4 & 9 & 12 & 84 \\
\hline 2 & & 25 & 7 & 10 & 8 & 72 \\
\hline 3 & & 25 & 8 & 11 & 6 & 68 \\
\hline 4 & & 25 & 8 & 10 & 7 & 68 \\
\hline 5 & & 25 & 9 & 10 & 6 & 64 \\
\hline 2 & \multirow{4}{*}{ Lemongrass encapsulate- 20 wash } & 25 & 9 & 10 & 6 & 64 \\
\hline 3 & & 25 & 10 & 7 & 8 & 60 \\
\hline 4 & & 25 & 8 & 5 & 12 & 68 \\
\hline 5 & & 25 & 9 & 6 & 10 & 64 \\
\hline 1 & \multirow[t]{5}{*}{ Lemongrass encapsulate-30 wash } & 25 & 11 & 4 & 10 & 56 \\
\hline 2 & & 25 & 8 & 5 & 12 & 68 \\
\hline 3 & & 25 & 9 & 10 & 6 & 64 \\
\hline 4 & & 25 & 8 & 7 & 10 & 68 \\
\hline 5 & & 25 & 9 & 10 & 6 & 64 \\
\hline
\end{tabular}

\section{Mosquitos}

exposing zone

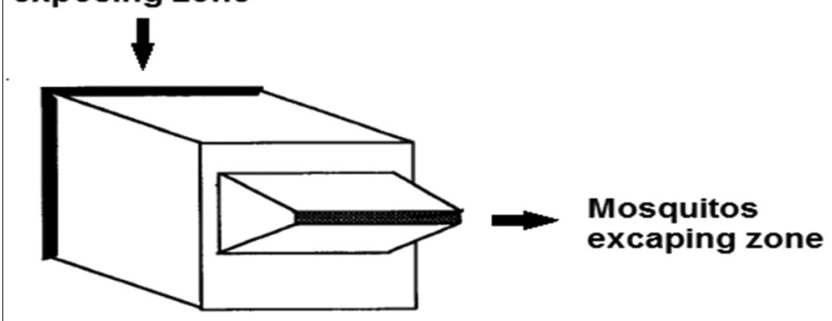

Fig. 1: Excito chamber used for mosquito repellency testing [14]

between these samples. It is understood that their difference between other sample is statistically significant $(\mathrm{F}=26.148, \mathrm{p}=0.00)$. Samples such as lemongrass-encapsulated fabric after 10 wash, lemongrassencapsulated fabric after 20 wash, and lemongrass-encapsulated fabric after 30 wash are shown slightly poor performance as compare with unwashed samples due to its loss of activity during washing. In post hoc analysis, it is understood that the difference between these three samples is statistically insignificant ( $\mathrm{p}$ values between these samples are $0.126,0.188$, and 0.995 ).

\section{Surface analysis of microencapsulated fabric}

The knitted cotton fabric after microencapsulated with lemongrass extract was analyzed through SEM analysis. Figs. 2-4 show the surface effect of treated fabric with different magnification level. In both the figures, particles were no longer visible on the surface but a thin layer covered with the fiber surface.

\section{GC analysis}

The chemical component identification of lemongrass extract was performed by GC-MS analysis, and the spectral data of these identified compounds were interpreted. Fig. 4 shows that 37 compounds and the chromatogram showed 47 peaks within the retention time of 6.69 minutes to 46.94 minutes. The major compound identified as 9,12-octadecadienoic acid (Z,Z) with around 15\% and n-hexadecanoic acid with $11.9 \%$ and lanosterol with $8 \%$. It is understood that from GCMS analysis the lemongrass extract compound was confirmed.
Comparative analysis of abrasion resistance of the mosquito repellent coated samples

Table 2 shows the abrasion resistance of various mosquito repellentcoated samples.

From the table, it is observed that lemongrass-coated sample after 30 wash showed the least performance than other samples but from the statistical point of view it is evident that the difference between the samples was insignificant (Since $\mathrm{p}<0.005$ )

\section{Bursting strength analysis}

Table 3 shows the bursting strength of various mosquito repellentcoated samples.

From the table, it is observed that controlled sample showed highest bursting strength performance than other samples. It is interpreted that the surface coating covers the air passage over the surface of the fabric and extensibility of the fiber/yarn is also get affected due to the outer coating of lemongrass extract, which reduces the bursting strength of the coated fabric.

\section{Air permeability analysis}

Tables 3 and 4 show the air permeability of various mosquito repellentcoated samples.

From the table, it is observed that controlled sample showed the highest porosity than other samples. It is interpreted that the surface coating covers the air passage over the surface of the fabric, so the air passage into the fabric was limited. After some wash, it is expected to peel off some coating on the surface of the fabric so that slight improvement in the air permeability was achieved.

\section{CONCLUSION}

Through this research work lemongrass-encapsulated cotton textile has got good mosquito repellent activity of $90 \%$ mosquito repellency activity. This microencapsulation technique provides better wash durability for the treated fabric even after 30 wash cycle that is even after 30 wash the reduction in mosquito repellency percentage was only $28.5 \%$. Other physical properties such as abrasion resistance due to washing will not statistically significant at $95 \%$ confidence 


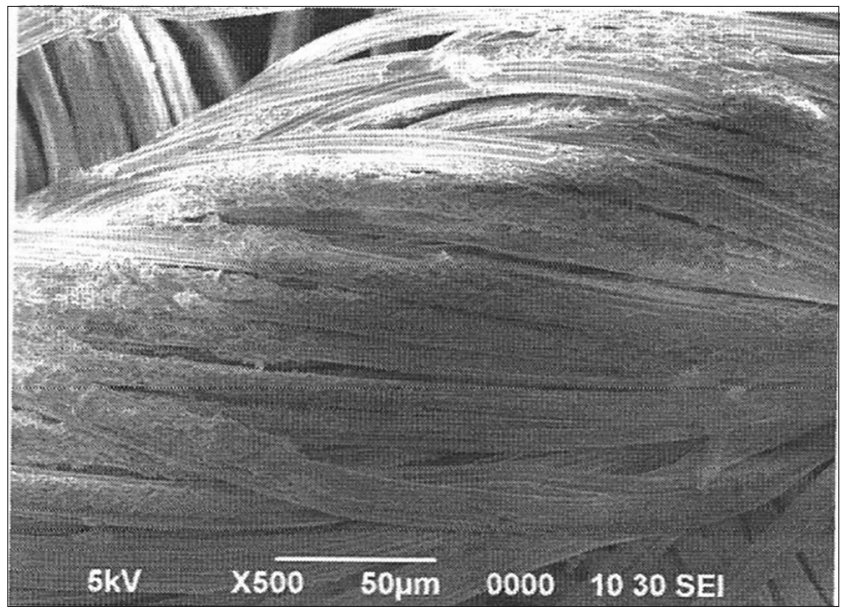

Fig. 2: Scanning electron microphotograph of lemongrass coated knitted fabric magnified $\times \mathbf{5 0 0}$

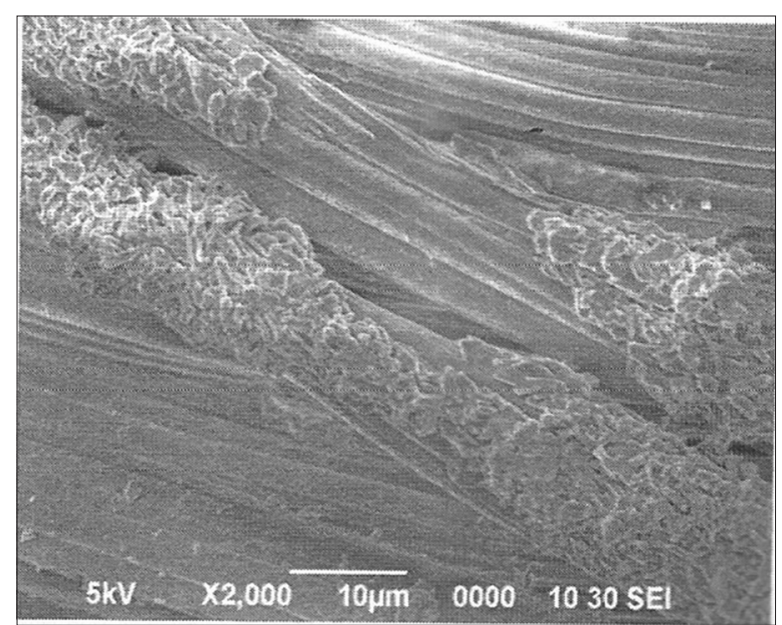

Fig. 3: Scanning electron microphotograph of lemongrass coated knitted fabric magnified $\times \mathbf{2 0 0 0}$ limit. However, slight property changes in bursting strength and air permeability due to microencapsulation on the textile structure. In

Table 2: Abrasion resistance of mosquito repellent finished samples

\begin{tabular}{llll}
\hline Fabric sample & $\begin{array}{l}\text { Weight } \\
\text { before } \\
\text { abrasion }\end{array}$ & $\begin{array}{l}\text { Weight } \\
\text { after } \\
\text { abrasion }\end{array}$ & $\begin{array}{l}\text { Weight } \\
\text { loss } \\
\text { (\%) }\end{array}$ \\
\hline Untreated sample & 5.15 & 5.06 & 1.75 \\
Lemongrass encapsulated & 5.10 & 5.00 & 1.96 \\
Lemongrass encapsulate-10 wash & 5.18 & 5.10 & 1.54 \\
Lemongrass encapsulate-20 wash & 5.16 & 5.06 & 1.94 \\
Lemongrass encapsulate-30 wash & 5.13 & 5.02 & 2.14 \\
Mean & & & 1.8660 \\
Significance p (0.05) & & & 0.000 \\
\hline
\end{tabular}

Table 3: Air permeability and porosity of the mosquito repellent finished samples

\begin{tabular}{|c|c|c|}
\hline Fabric sample & $\begin{array}{l}\text { Air permeability } \\
\left(\mathrm{cm}^{3} / \mathrm{cm}^{2} / \mathrm{s}\right)\end{array}$ & $\begin{array}{l}\text { Porosity } \\
(\%)\end{array}$ \\
\hline Untreated sample & $244.75 \pm 0.30$ & 86.24 \\
\hline Lemongrass encapsulated & $245.23 \pm 0.31$ & 84.36 \\
\hline Lemongrass encapsulate after 10 wash & $245.83 \pm 0.29$ & 84.45 \\
\hline Lemongrass encapsulate after 20 wash & $244.95 \pm 0.29$ & 84.75 \\
\hline Lemongrass encapsulate after 30 wash & $242.23 \pm 0.30$ & 86.18 \\
\hline
\end{tabular}

Table 4: Bursting strength of the mosquito repellent finished samples

\begin{tabular}{ll}
\hline Fabric sample & $\begin{array}{l}\text { Bursting strength } \\
\text { (kg/sq.cm) }\end{array}$ \\
\hline Untreated sample & $6.24 \pm 0.11$ \\
Lemongrass encapsulated & $5.65 \pm 0.09$ \\
Lemongrass encapsulate after 10 wash & $5.90 \pm 0.05$ \\
Lemongrass encapsulate after 20 wash & $5.65 \pm 0.08$ \\
Lemongrass encapsulate after 30 wash & $5.20 \pm 0.04$ \\
\hline
\end{tabular}

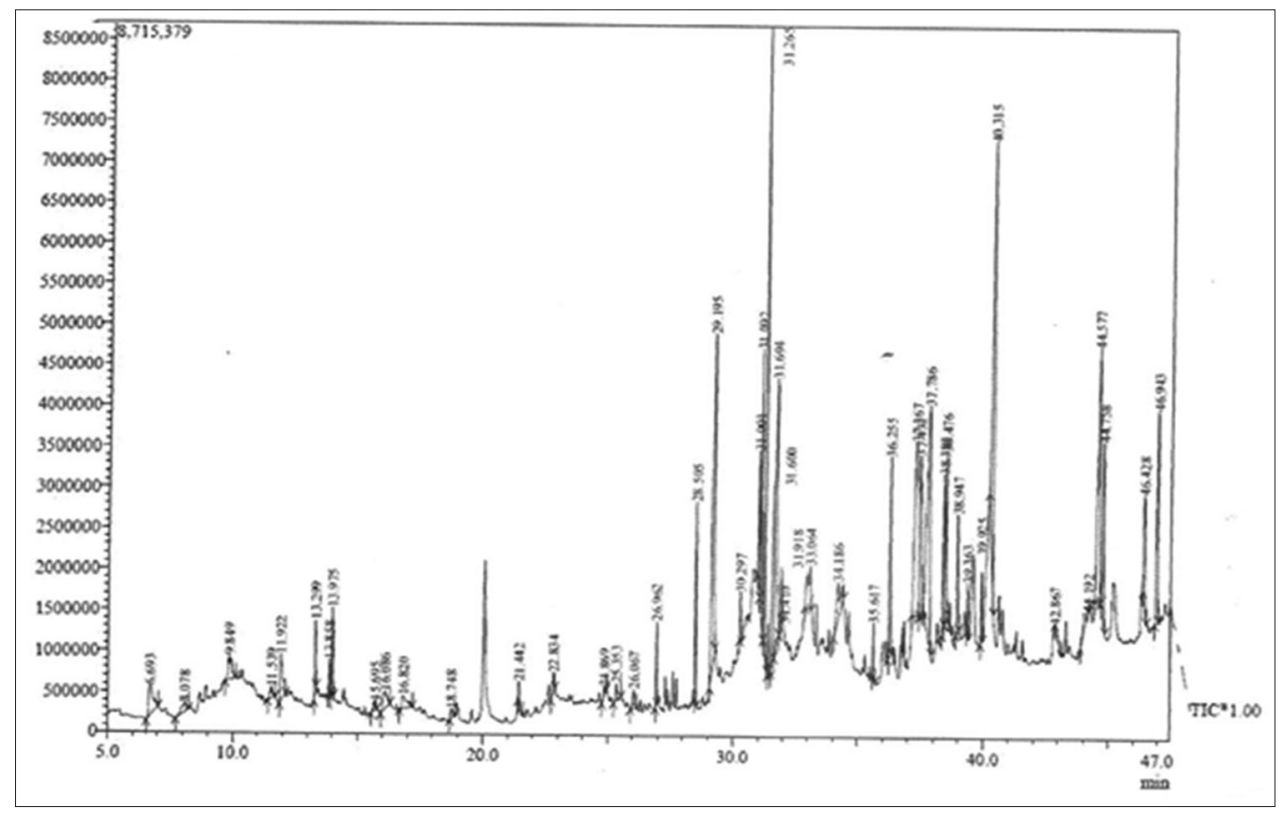

Fig. 4: Chromatogram of gas chromatography mass spectrum analysis of lemongrass extract 
overall aspect, the natural form of extraction of the microencapsulated coating is very safe and eco-friendly.

\section{REFERENCES}

1. Maheshwaran R, Sathish S, Ignacimuthu S. Larvicidal activity of Leucas aspera (willd) against the larvae of Culex quinquefasciatus Say. And Aedes aegypti L. Int J Integr Biol 2008;2:214-7.

2. Bernhard L, Bernhard P, Magnussen P. Management of patients with lymphoedema caused by filariasis in North-Eastern Tanzania: Alternative approaches. Physiotherapy 2003;89(12):743-9.

3. Farag SA, Osama H, Mohamed R, Mohamed H. Development of longer-lasting insect repellence cellulosic based curtain fabrics. Mater Sci Appl 2011;2(3):200-8.

4. Amer A, Mehlhorn H. Larvicidal effects of various essential oils against Aedes, Anopheles, and Culex larvae (Diptera, Culicidae). Parasitol Res 2006;99(4):466-72.

5. Brown M, Hebert AA. Insect repellents: An overview. J Am Acad Dermatol 1997;36(2),243-9.

6. Rajendran R, Radhai R, Rajalakshmi V. Development of mosquito repellent fabrics using Vitex negundo loaded nanoparticles. Malaya J Biosci 2014;1(1):19-23.

7. Specos MM, García JJ, Tornesello J, Marino P, Vecchia MD, Tesoriero MV, et al. Microencapsulated citronella oil for mosquito repellent finishing of cotton textiles. Trans $\mathrm{R}$ Soc Trop Med Hyg 2010;104(10):653-8.

8. Prajapati V, Tripathi AK, Aggarwal KK, Khanuja SP. Insecticidal, repellent and oviposition-deterrent activity of selected essential oils against Anopheles stephensi, Aedes aegypti and Culex quinquefasciatus. Bioresour Technol 2005;96:1749-57.

9. Haridasan P, Gokuldas M, Ajaykumar AP. Antifeedant effects of vitex negundo L. Leaf extracts on the stored product pest, Tribolium castaneum H. (Coleoptera: Tenebrionidae. Int J Pharm Pharm Sci 2017;9(3):17-22

10. Thilagavathi G, Krishna BS, Kannaian T. Microencapsulation of herbal extracts for microbial resistance in healthcare textiles. Indian J Fibre Text Res 2007;32:351-4

11. Ramya K, Maheshwari V. Development of eco-friendly mosquito repellent fabric finished with Andrographis paniculata plant extracts. Int J Pharm Pharm Sci 2014;6(5):115-7.

12. Pharmacopoeia, British. Her majesty's stationery office, London. p. A55 (1980).

13. Golja B, Šumiga B, Tavčer PF. Fragrant finishing of cotton with microcapsules: Comparison between printing and impregnation. Coloration Technol 2013;129(5):338-46.

14. Roberts DR, Chareonviriyaphap T, Harlan HH, Hshieh P. Methods of testing and analyzing excito-repellency responses of malaria vectors to insecticides. J Am Mosq Control Assoc 1997;13(1):13-7. 